\title{
SOBRE A NARRATIVA RIZOMÁTICA DE ANTÓNIO LOBO ANTUNES
}

\section{ABOUT THE RHIZOMATIC NARRATIVE OF ANTÓNIO LOBO ANTUNES}

Raquel Trentin Oliveira ${ }^{1}$

\begin{abstract}
RESUMO
O presente artigo debruça-se sobre um romance de António Lobo Antunes, Que cavalos são aqueles que fazem sombra no mar? (2009), no intuito de perceber até onde tem ido sua experimentação romanesca, capaz de desmontar, definitivamente, a estrutura da narrativa tradicional e abalar os protocolos de leitura convencionais. Para tanto, parte das discussões teóricas de Umberto Eco sobre "obra aberta" e "obra em movimento", de Roland Barthes sobre "texto de fruição" e de Deleuze e Guattari sobre "livro-rizoma”.
\end{abstract}

PALAVRAS-CHAVE: narrativa contemporânea, António Lobo Antunes, "livro-rizoma"

\begin{abstract}
This paper analyses the novel Que cavalos são aqueles que fazem sombra no mar? (2009), by António Lobo Antunes, in order to understand how far his formal experimentation has gone, able to definitively dismantle the structure of the traditional narrative and the conventional reading protocols. Therefore, the theoretical foundations are based on the discussion of Umberto Eco about "open work" and "work in movement", Roland Barthes about "text of fruition", and Deleuze and Guattari about "book rhizoma".
\end{abstract}

KEYWORDS: Contemporary narrative, António Lobo Antunes, book rhizoma. 
"Desde O Manual dos Inquisidores não me interessa a intriga, a história. O que quero é colocar a vida inteira entre as capas de um livro."

António Lobo Antunes (entrevista ao jornal O Estado de São Paulo, em 23 de abril de 2006.)

1. Ainda nas décadas de 1960/1970, autores como Roland Barthes e Umberto Eco apontavam diferenças fundamentais na forma narrativa contemporânea em relação às formas da narrativa "clássica" ${ }^{2}$ Com a concepção de "obra aberta" e mais especificamente "obra em movimento" (ECO, 2013), e com a concepção de "texto de fruição" (BARTHES, 2013), ambos valorizaram o maior espaço assumido pelo leitor na interpretação e na "execução" dessas obras. Nas palavras de Eco, é claro que toda obra de arte exige uma resposta livre e inventiva do leitor, mas a estética contemporânea, com uma mais madura consciência crítica dessa liberdade, "ao invés de sujeitar-se à abertura como fator inevitável, erige-a em programa produtivo e até propõe a obra de modo a promover a maior abertura possível" (ECO, 2013, p. 42). O presente artigo debruça-se sobre um romance de António Lobo Antunes, Que cavalos são aqueles que fazem sombra no mar? (2009), no intuito de perceber até onde tem ido sua experimentação romanesca, capaz de desmontar, definitivamente, a estrutura da narrativa tradicional e abalar os protocolos de leitura convencionais.

Assim, Umberto Eco acentua o esgotamento, em meados do século XX, de uma poética de moldes aristotélicos, lendo obras como as de Kafka, Joyce e Brecht como "abertas por excelência”, pois a um "mundo ordenado segundo leis universalmente reconhecidas substitui-se um mundo fundado sobre a ambiguidade, quer no sentido negativo de uma carência de centros de orientação, quer no sentido positivo de uma contínua revisibilidade dos valores e das certezas" (ECO, 2013, p. 47). Nesse contexto, o autor destaca ainda uma categoria mais restrita de obras, definidas por ele como "em movimento", por sua capacidade de assumir diversas formas imprevistas, "reproduzir-se caleidoscopicamente aos olhos do fruidor como eternamente novas" (ECO, 2013, p. 51), perdendo-se totalmente a intenção de controle do autor. Além de exemplos da música experimental e das artes plásticas, o autor evoca uma antecipação novecentista: o Livre idealizado por Mallarmé, texto sem começo nem fim, móvel e permutável em suas partes, onde não se devia encontrar nenhum sentido fixo, nenhuma forma definitiva.

Umberto Eco vê nessa poética da obra aberta - e mais ainda, da obra em movimento -, que a cada fruição se apresenta sempre diferente de si mesma, as ressonâncias indefinidas de algumas das tendências do pensamento científico contemporâneo, entre elas: a noção de campo provinda da física, que questiona as relações de causa e efeito unívoca e unidirecionalmente entendidas, "implicando, ao contrário, a ideia de um complexo interagir de forças, uma constelação de eventos, um dinamismo de estrutu- 
ra” (ECO, 2013, p. 56); a noção filosófica de possibilidade, com o abandono de uma visão estática e silogística da ordem, "a abertura para uma plasticidade de decisões pessoais e para uma situacionalidade e historicidade de valores" (ECO, 2013, p. 56); o princípio físico da complementaridade, segundo o qual para descrever comportamentos diversos valem diversos modelos, "que são portanto justos quando utilizados no lugar apropriado, mas se contradizem entre si e se chamam, por isso, reciprocamente complementares" (HEISEMBERGER, apud ECO, 2013, p. 57); a noção de descontinuidade da física, "aspecto ineliminável de toda verificação científica e como comportamento verificável e insofismável do mundo subatômico" (ECO, 2013, p. 57); o conceito de ambiguidades perceptivas, da psicologia e da fenomenologia, que valoriza a plurivalência das percepções e a contínua mutação dos fenômenos (ECO, 2013, p. 58).

Enfim, Umberto Eco identifica na poética da obra aberta um diálogo com o pensamento científico seu contemporâneo no sentido de valorizar a noção de indeterminação: "a abertura e o dinamismo de uma obra consistem em tornar-se disponível a várias integrações, complementos produtivos concretos, canalizando-os a priori para o jogo de uma vitalidade estrutural que a obra possui, embora inacabada, e que parece válida também em vista de resultados diversos e múltiplos" (ECO, 2013, p. 63).

Essa tendência realmente se ramificou sobremaneira no romance da última metade do século XX e início do XXI, e uma retomada breve de alguns elementos formais aí recorrentes confirma isso:

- predominância da focalização interna e/ou externa, com acentuação do caráter parcial, incerto, vago das informações narrativas;

- multiplicação das perspectivas, ao ponto de, por vezes, não ser possível identificar a origem da percepção;

- mistura incessante de tempos e lugares, dificultando a contextualização segura, ou, mais recorrentemente, ausência de dados temporais e espaciais precisos;

- valorização da elipse e da consequente fragmentação e descontinuidade da narrativa;

- fusão dos diferentes movimentos da narrativa - cena, sumário, pausa descritiva, comentário reflexivo, tornando-se por vezes indiscernível a história propriamente dita;

- ausência de introdução ou acabamento da história e acentuação do caráter incompleto e indeterminado da ação;

- imprevisibilidade no desenvolvimento da história, enfraquecimento ou anulação das relações de causalidade, ordem e progresso;

- desfiguração do retrato da personagem: uso muito restrito ou ausente da caracterização direta; distorção da função de agente, com predominância de uma imagem contraditória e desconforme da personagem; 
- libertação da pontuação convencional e dos efeitos de pausa e entonação a ela associados, o que muitas vezes se associa à ausência de sinais diferenciais do discurso direto ou indireto (verbo dicendi, aspas, dois-pontos, travessão etc.)

- mistura aparentemente aleatória de distintas formas tipográficas;

- ruptura na distribuição esperada das linhas: ausência de marcas de paragrafação; distribuição aparentemente arbitrária de espaços em branco; utilização de linhas muito curtas, por vezes restritas a uma palavra ou expressão, ou extremamente extensas, chegando a tomar o livro inteiro;

- hibridismo de gêneros e estilos;

- investimento na ironia, na paródia e no pastiche;

- exploração de categorias do insólito - maravilhoso, fantástico, gótico, absurdo, estranho, etc., em contextos predominantemente "normais", "naturais";

- acento da noção de arbitrariedade ficcional e autorreflexividade narrativa.

Com tais tendências, muitas vezes, fica difícil aplicar diretamente na análise do texto algumas das teorias formais ou estruturalistas da narrativa (que nos legaram, por exemplo, as noções de "sequências narrativas", "predicados de base", "funções cardinais", "ordem"), baseadas no estudo da narrativa clássica, ainda que estas sirvam de referência para perceber o que mudou. Isso pede, ao leitor, que se dispa de certas expectativas em relação à forma da narrativa ou do livro, abrindo-se a uma poética desprovida de resultado necessário e/ou previsível: "cada execução a explica mas não a esgota, cada execução executa a obra mas todas são complementares entre si, enfim, cada execução nos dá a obra de maneira completa e satisfatória, mas ao mesmo tempo no-la dá incompleta" (ECO, 2013, p. 57).

Essa imprevisibilidade da forma narrativa e a diluição de seus eixos estruturais e semânticos lembram-nos o que Deleuze e Guattari (2011) definiram como "livro-rizoma", pressupondo uma diferença entre este, o "livro-raiz" (com uma bela interioridade orgânica, fundado na imitação acabada do mundo, em uma lógica binária) e o "livro-radícula" (sem raiz principal, mas com unidade suposta, possível de ser encontrada numa dimensão suplementar ou superior). Ao contrário dos últimos, o "livro-rizoma” configuraria um sistema acentrado, sem unidade pressuposta. Ele não é feito de unidades, mas de dimensões, ou antes, direções movediças:

oposto a uma estrutura, que se define por um conjunto de pontos e posições, por correlações binárias entre esses pontos e relações biunívocas entre essas posições, o rizoma é feito só de linhas: linhas de segmentariedade, de estratificação, como dimensões, mas também linhas de fuga ou de desterritorialização como dimensão máxima segundo a qual, em seguindo-a, a multiplicidade se metamorfoseia, mudando de natureza (DELEUZE; GUATTARI, 2011, p. 43) 
Conexão, ruptura, heterogeneidade, multiplicidade são os princípios de um livro-rizoma. Aos olhos do leitor, o livro-rizoma tem múltiplas entradas, é aberto, "conectável em todas as suas dimensões, desmontável, reversível, suscetível de receber modificações constantemente" (DELEUZE; GUATTARI, 2011, p. 30).

2. No caso do romance português, Cristina Robalo Cordeiro, num artigo intitulado "Os limites do romanesco" (1997), já chamava a atenção para o processo de erosão e renovação que atinge a narrativa em Portugal em função do destaque que nela ganha a "pura textualização", o princípio da autorreferencialidade e da produtividade significante da palavra. Incluindo nesse contexto desde O rumor branco (1962), de Almeida Faria, até Um beijo dado mais tarde, de Maria Gabriela Llansol (1990), a autora ressalta a atenuação ou expulsão definitiva de formas tradicionalmente constitutivas do romance:

laboratório da narrativa, local privilegiado de viva experimentação, o (um certo tipo de) romance vem encenando, desde a década de 60, uma espécie de experiência dos limites que passa forçosamente pela contestação e desmoronamento da prática romanesca tradicional que refletia a estabilidade de um mundo de equilíbrio inabalável, e pela recusa da imposição de leis rígidas e de significações preconcebidas. $\mathrm{Ne}$ gando-se a ser modo de representação do real por excelência, e procurando igualmente contestar, em reação às anteriores realizações neo-realistas, os limites ideológicos impostos por qualquer tipo de literatura meramente comprometida, estes novos textos, não reconhecendo ao narrador uma função demiúrgica, rejeitam as regras de intriga tranquilamente bem montada, o desenho da personagem como cristalização de um carácter e polo aglutinador da ação, a descrição metonímica de um espaço potencialmente apto a representações econômico-sociais e em estreita conexão com a vida psicológica das figuras que o povoam e a concepção de tempo na linearidade de um devir temporal. Estes romances que a crítica cada vez mais designará por textos, urdidos num processo extremamente pessoal e complexo, instauram ainda um violento atentado aos protocolos tradicionais da leitura, desconcertando ou mesmo afastando quem não se disponha a um esforço continuado de atenção (de associação e decifração) (CORDEIRO, 1997, p. 111-112).

A essa tendência, a autora liga um complexo e proteiforme jogo de influências - que vai do nouveau roman francês e a sua exploração ao extremo de alguns preceitos modernistas, à influência das artes plásticas, do cinema, da linguística estruturalista e de uma nova concepção de leitura - para concluir: "do primado de uma universalidade ordenada, da ideia, postulada pela ciência e filosofias positivistas do século XIX, da unidade fundamental do ser e do mundo à instauração definitiva dos conceitos de 
probabilidade, de relatividade e indeterminação, utilizados para reproduzir o cepticismo quanto à possibilidade de uma visão segura do real" (CORDEIRO, 1997, p. 116).

A romanesca de António Lobo Antunes é, sem dúvida, uma das poéticas mais desconcertantes da literatura portuguesa contemporânea, cuja trajetória é continuamente lida e relida (SEIXO, 2002; CABRAL et al, 2003; CAMMAERT et al, 2011), em si mesma surpreendendo pela multiformidade e o amplo potencial de entradas. Mas se os primeiros romances, como Os cus de Judas e Fado Alexandrino, já espantavam o leitor por suas singularidades temáticas e formais, o que dizer dos últimos, tanto que já são acusados de dificultar a acessibilidade e limitar a recepção. ${ }^{3}$ Recorto dessa fase o livro Que cavalos são aqueles que fazem sombra no mar? (2009), na tentativa de qualificar provisoriamente a sua forma indeterminada e descontínua, a conexão bastante variável de suas linhas e a liquefação dos sentidos.

Como leitora, tenho a impressão de que, para entrar nesse romance, é preciso deixar-se "flutuar à deriva". A primeira linha da história já evoca outra história que se conecta a muitas mais. O primeiro eu que fala (a filha Beatriz, que só será nomeada pelo irmão no capítulo seguinte) começa por evocar a palavra de outro eu (a mãe) que, por sua vez, retoma outros (a avó e a bisavó), num enlace de gerações e tempos, de algum modo ironizado, ao modo de Samuel Beckett, ${ }^{4}$ por quem quer que seja o enunciador perdido nesse emaranhado de vozes:

- Sou eu
mas a quem pertence o eu que segredava
- Sou eu.
E quem somos nós sem boca sem olhos nem substância de
carnes... (ANTUNES, 2009, p. 14)

É nesse entre-lugar, nesse limiar de tempos e vozes, que os enunciadores narrativos se colocam. No primeiro capítulo, por exemplo: das lembranças do que a mãe contava no passado, Beatriz supõe o atual esquecimento dela, prestes a morrer no hospital, passando logo a lembrar-se pela mãe; da imaginação de uma pergunta do pai diante da mãe no hospital chega à lembrança de que ele nunca perguntava nada e nunca decidia nada; o costumeiro ensimesmamento paterno mistura-se à inexpressão da mãe, imóvel no hospital; a percepção dos resmungos maternos diante dos cuidados médicos evoca a lembrança dos gritos dos empregados com os cavalos da quinta, numa infância perdida; a reminiscência das alianças escorregadias da mãe e do pai faz recordar os próprios casamentos falhados; a peremptória afirmação do esquecimento e do desamor modaliza-se no reconhecimento de momentos de carência e saudade; a menção aos maridos (não)esquecidos confunde-se com a lembrança do pai, dos cavalos e da complicada situação da quinta naquele momento de crise familiar; a lembrança da morte dos touros na quinta se embaralha com a imaginação da morte da mãe, e assim sucessivamente. Enredadas, sem hierarquia e separações, insinuam- 
-se voltas e voltas no tempo, vultos e ecos, imagens que se materializam e logo se desfiguram. Soltos no meio disso tudo, cintilam furtivamente alguns lampejos de lucidez como estes: "que estranho viver, como se faz, começa-se por onde, em que capítulo"; "como tudo me foge", "ecos que não significam nada ou significam o que me escapa e todavia existe".

Assim se intensifica também no leitor a sensação da inapreensibilidade dos acontecimentos e das personagens, alimentada por um campo semântico do imprevisível e do incerto que se ramifica já nas primeiras páginas: "penumbra", "mistérios", "sonhos", "resmungo", "impressão", "sombra”, "desordem”, “nódoas”, "desvão", "hesitação", "poeira”, "fragmentos indecisos", "incompreensão", "espanto", "cintilação furtiva", "acaso", "ecos", "pregas", etc. Ao mesmo tempo e associadas a tal campo, imagens se cristalizam e fulguram na sua materialidade intensa: "brilho da saliva", "patas dos animais a trotarem no soalho", "tubo da garganta", "galope dos cavalos vindo das estrebarias", "cancro", "alianças na fronha", "toiro encostado a uma azinheira de baba a pingar do nariz", "osso na algibeira do avental", "chuva na cama da minha mãe", "cuspo de sangue", "berros", "faqueiro de prata", "apartamento cheio de pregos nas paredes", "cartas atadas num cordel de embrulho", "um gato que nos ilumina a nós com as lamparinas dos olhos, e assim por diante.

Basta observar isso para entender que a história é dada como um fluxo, sem início e sem fim, em que coexistem e se interconectam percepção ordinária, recordação, fantasia, reflexão e afetividade, ${ }^{5}$ ligadas a momentos temporais que remetem continuamente, através de seus horizontes, a outros. Assim, a narração da história evidencia a noção de impossibilidade de síntese, de acabamento, estando seus horizontes sempre abertos e propensos à fuga. Isso não significa, é claro, a pura aleatoriedade ou a irrelevância semântica da associação de imagens. Pelo contrário, os dados justapostos (como aqueles antes referidos) podem ser lidos nas suas relações de semelhança, diferença, complementariedade, sinalizando, por exemplo, a complexidade das relações afetivas, a vulnerabilidade da condição humana, a degradação de bens materiais, o desgaste e a revisão de valores, etc.

As recordações não se referem a um mesmo período temporal, mas invocam múltiplos tempos, sem delimitá-los e/ou datá-los: a lembrança da lembrança da lembrança, como se caísse num abismo temporal. José Gil, quando analisa outro dos romances do autor, o Arquipélago da Insônia (2008), explica muito bem tal formato, ligando-o à potencialidade da escrita:

são ilhas de tempos que se conectam pelo poder hipnótico da bruma que a escrita segrega. Porque a escrita cria uma bruma de tempo, todos os tempos podem ser evocados e surgidos na bruma. Cada cena é uma ilha e o conjunto um arquipélago sem fim. Saídos da bruma, mas totalmente envoltos ainda nela, são como imagens nascidas de uma insônia, mal situadas no espaço e no tempo, vacilantes, fantasmáticas (GIL, 2011, p. 161). 
Nessa perspectiva, podemos ler a configuração de outros elementos da narrativa. Que cavalos são aqueles que fazem sombra no mar? apresenta-se como um mosaico de histórias contadas por integrantes de uma mesma família - filhos (Beatriz, Ana, Rita, João, Francisco, "bastardo"), pais, criada. Cada execução conta parte da história dessa família, mas não a esgota, sendo todas complementares entre si e ao mesmo tempo incompletas. Assim, a imagem das personagens se renova continuamente aos olhos do leitor, como uma espécie de caleidoscópio existencial: "eu não uma, várias alterando-se a cada instante" (ANTUNES, 2009, p. 192). A imagem da mãe, por exemplo, é construída pelos diferentes olhares dos filhos, do marido, da criada e de si mesma. Tais visões, no entanto, não caracterizam a mãe diretamente, mas por meio da alusão a traços dela - rápidos gestos, palavras soltas, comportamentos inusitados - que impressionaram/ impressionam seus familiares. Desse modo, os acontecimentos da trajetória existencial da personagem ganham diferentes modulações conforme a percepção de cada um dos que com ela se relacionam/relacionaram, e esta mesma percepção pode modificar-se em cada nova atuação dos narradores. Ao mesmo tempo, no entanto, certas designações se repetem como um refrão, circulando entre os diferentes narradores, como se dissessem de um traço mais forte, reconhecível e compartilhado pela família: por vezes, revelando-se como estereótipos (Beatriz é associada à gravidez precoce, João à homossexualidade, Ana ao uso de drogas, o pai ao jogo, por exemplo); por vezes, como obsessões íntimas (João: "e mesmo continuando a pecar Deus há-de perdoar-me”, [ANTUNES, 2009, p. 67]; Francisco: "não me sinto da família, sinto-me uma excrescência, um intruso", [ANTUNES, 2009, p. 108]). Assim, os dados são também repetidos, atualizados, modalizados, revertidos, sinalizando preconceitos, carências, culpas, segredos; bem longe, contudo, de configurarem uma imagem estável dos protagonistas.

Tal fórmula de figuração do conteúdo existencial das personagens torna-se mais surpreendente porque não se estabelecem diálogos efetivos entre elas, confrontos ou acusações diretas. Há, isto sim, familiares estranhos que conversam "frases e frases no interior do silêncio" (ANTUNES, 2009, p. 181); indignação, ressentimento, ódio, mas também ternura, preocupação, saudade - sentimentos que se adensam na intimidade muda, talvez por não se resolverem em uma expressão franca. Se o diálogo é mínimo, também o são outros tipos de ações externas. Inferimos gestos, movimentações, atitudes, aludidos, contudo, ainda como puras intenções ou já como restos: "o que não chega a ser quase sendo e o que deixou de ser sendo ainda” (ANTUNES, 2009, p. 335).

Nesse fluxo, perdem-se também os limites entre as vozes. Marca da narrativa loboantunense, tal processo vem se tornando ainda mais complexo nos últimos romances, ${ }^{6}$ sendo difícil por vezes desenredar a voz do eu da voz de um outro, de outros. No romance em estudo, por exemplo, está uma personagem a narrar em determinado capítulo, quando outra começa a narrar, seguindo assim sem forma explícita de coordenação ou 
subordinação. Percebemos que a narração mudou geralmente pelo modo de referência, nem tanto a si, mas sobretudo aos outros. Dou apenas um exemplo dos muitos presentes em Que cavalos são aqueles que fazem sombra no mar. Está Francisco a narrar quando se lembra de uma história que a mãe costumava contar: "sempre que contava uma história e adorava contar esta história [...] a minha mãe mudava de posição no sofá [...], a vossa avó em pequena, costumava acompanhar a minha avó nas visitas que a senhora faziam" (ANTUNES, 2009, p. 178, grifo meu). Isto é, sem sinalização gráfica (aspas, travessão, verbo dicendi), a narrativa passa da voz do filho, que detectamos por sua alusão à mãe, para a voz da mãe, que conta a história que contava no passado sobre uma visita que fazia com a avó a casa de uma amiga dela. O rastro de subordinação da voz da mãe à do filho logo se perde, no entanto, ainda mais porque, na sequência, há mudança do contexto espaço-temporal da infância da mãe para o contexto espaço-temporal da casa em que vivia com o marido e os filhos: "como esta casa deve ser triste às três horas da tarde, ou seja, o que eu sinto debruçada para o telefone a perguntar..." (ANTUNES, 2009, p. 180); e ainda para o contexto espaço-temporal do hospital, o que parece constituir o presente da narrativa e no qual ela aguarda a morte: "enquanto não me virem num caixão não descansam" (ANTUNES, 2009, p. 180). Repentinamente, sem nenhum sinal de mediação, detectamos o retorno da voz de Francisco por sua referência à irmã - "depois da ponta do cigarro a minha irmã Ana saía da capoeira..." (ANTUNES, 2009, p. 181, grifo meu) - que segue narrando.

Com isso, fica-nos a impressão de que uma voz não se fecha em si, não se isola em seu contexto de enunciação, mas aponta sempre para outra voz, que arrasta consigo contextos espaço-temporais particulares. $\mathrm{Ou}$ ainda, cada personagem é constituída com referência ao vestígio que contém de outras personagens. A forma de tal interconexão difere bastante das convenções narrativas tradicionais, porque não se configuram, na história, cenas de interlocução que introduziriam, explicitamente, o interesse de ouvir e a intenção de contar uma história, ou de discutir, afirmar e replicar qualquer assunto. Como no exemplo citado, as personagens encontram-se em contextos de enunciação diversos e, mesmo que a alusão de uma a outra conecte-as inicialmente, só a arbitrariedade ficcional justificaria o rumo relativamente independente e singular da narração intercalada. Porém, tal narrativa não conta com um narrador extradiegético - aquele deus criado pela ficção para transcender todos os limites que a verossimilhança impõe.

Esse parece ser um dos sinais do esfacelamento dos limites do campo diegético e também das regras de verossimilhança tradicionalmente aplicáveis à narração e/ou à focalização interna. Apesar de confinadas nos limites da história, do seu campo de experiência/percepção, em diversos momentos, as personagens demonstram consciência do quanto resultam de estratégias extradiegéticas: "eis o António Lobo Antunes a saltar frases não logrando acompanhar-me e a afogar num tanque os gatinhos do que sinto" (ANTUNES, 2009, p. 22). Assim, problematiza-se também o pacto de rea- 
lidade estabelecido pelo leitor com o texto, visto que as próprias personagens, apesar de seu conteúdo humano tão crível, se apresentam como seres de papel: "é um livro, e eu uma criatura do livro, não uma pessoa a sério" (ANTUNES, 2009, p.143). Para José Gil, em consequência disso, “o leitor oscila entre a presença de um referente ou a sua impresença, que redunda, assim, numa pura ficção inconsistente - restando só a omnipotente, visível e tangível máquina da escrita" (2011, p. 169). Diríamos nós que tal paradoxo se acentua em Que cavalos são aqueles que fazem sombra no mar?: sem dúvida, a personagem tem consciência da dependência da sua voz do mando do autor ("é o que escreve quem manda e ordenou-me que falasse como ordenou aos outros" ANTUNES, 2009, p. 254), mas também do quanto o autor depende dessa mesma voz e a ela está atrelada: "não é o que escreve o livro, sou eu que narro isto, o do livro a juntar palavras e o que significam palavras, convencido que a voz desloca sozinha e não desloca" (ANTUNES, 2009 , p.256). O texto assim mostra-se na sua urdidura complexa, em que cada voz é sempre também outras vozes e por baixo dessas vozes sempre outras ocultas, conectando, enfim, o dentro do livro com o fora do livro e dando ao leitor a sensação de caminhar em território não balizado.

O rompimento desse limiar pode ser conectado a outro: das fronteiras entre morte e vida. As personagens vivas na história por vezes se apresentam como mortas, por terem consciência da lógica inexorável da escrita: "ninguém nos chama já, na última página do livro o que fomos acabou, o tempo dos relógios para os outros somente" (ANTUNES, 2009, p. 158): "é provável que todos nós mortos [...] este é um romance de espectros, quem o escreve por mim" (ANTUNES, 2009, p.130). Ao mesmo tempo, se reconhecem feitas de matéria viva e perecível, temendo e imaginando a própria finitude: emagreço, olhe as covas nas bochechas e quadris [...] sequei, abata-me com o machado (ANTUNES, 2009, p.124); “a minha mãe [...] dois embrulhos de tendões e falanges em que daqui a pouco moscas e formigas como o bezerro que encontrei num valado e em torno dele raposas [...] e eu um bezerro num valado com raposas em torno (ANTUNES, 2009, p. 140-141). Por outro lado, os mortos ganham vida como se ressuscitados pela imaginação/memória dos vivos: "o meu pai mesmo defunto a tirar o casaco do cabide" (ANTUNES, 2009, p.241); ou pela habilidade ficcional: "parece que é a minha vez de falar [...] trazem o meu nome da gaveta dos mortos" (ANTUNES, 2009, p.221). É assim que Rita e o pai, já mortos, têm o direito de dar a sua versão dos fatos em dois dos capítulos do romance; ela, aliás, narra a passagem inenarrável, como se sua consciência sobrevivesse ao corpo: "o enfermeiro dos bombons a arrancar-me os tubos enquanto o capelão guardava as bençãos na pasta - Está com Deus" (ANTUNES, 2009, p.229); e avalia seu estado pós-morte: "ao chegar aqui, pensei: - Se calhar encontro o meu pai e não encontro nunca, fica-se sem companhia como na vida" (ANTUNES, 2009, p.222). 
Nessas ocasiões, em que a narrativa acentua o artifício do ficcionista ("é o que escreve quem manda e ordenou-me que falasse [Ana] como ordenou aos outros, mesmo à Rita e ao pai”, ANTUNES, 2009, p. 254), o romance parece assumir traços do que a narratologia contemporânea tem chamado de "unnatural narrative". Em comparação com narrativas anteriores, alguns textos modernistas e especialmente pós-modernistas adquirem a sua especificidade através da concentração e radicalização da artificialidade. A "unnatural narrative” viola leis da física, princípios lógicos ou limitações antropomórficas padrões, representando narradores, personagens, temporalidades ou espaços que exigem uma modificação das concepções narratológicas existentes, por ousarem e abusarem do uso de impossibilidades que ainda não foram convencionalizadas, ou seja, transformadas em estruturas cognitivas básicas e, portanto, ainda nos parecem estranhas (ALBER, 2013). Nos romances de Lobo Antunes, isso fica evidente, por exemplo, na narração telepática das personagens principais; de personagens cadáveres que falam; de montagens espaço-temporais que interligam zonas temporais muito diferentes, assim como lugares que sabemos separados, desafiando as noções clássicas de tempo e espaço (recursos caracterizadores da "unnatural voice" (cf. RICHARDSON, 2006).

Retornamos ao comentário de Lobo Antunes, posto em epígrafe, para acentuar a maneira como escolhemos entrar nesse seu romance: Lobo Antunes rompe com convenções narrativas esperadas e entrega-nos uma experiência mais próxima do seu estado potencial, caótico e complexo. Para tanto, sua narrativa atrela-se àquela categoria de livro rizomático que, segundo Deleuze e Guattari, sabe "mover-se entre as coisas, instaurar uma lógica do E, reverter a ontologia, destituir o fundamento, anular fim e começo" (2011, p.49). Contra os sistemas narrativos centrados e mesmo policentrados, de comunicação hierárquica e ligações preestabelecidas, seu romance se faz sem limites precisos, na intersecção de devires existenciais e cadências afetivas (instigando no leitor aquele idealizado agenciamento do livro com a "vida inteira"). Nega-se a estruturalizar a experiência em individualidades fechadas, a neutralizar as multiplicidades segundo eixos semânticos determinados, valorizando, isto sim, os impasses, as brechas, as direções movediças. Pede, assim, ao leitor uma consciência crescente da descontinuidade, da não linearidade, da diferença, da necessidade do diálogo como dimensões operativas da construção dos sentidos do texto e do real, sempre aberta a linhas de fuga e a novas entradas.

\section{REFERÊNCIAS BIBLIOGRÁFICA}

ALBER, Jan. Unnatural narrative. In: HÜHN, Peter et al. The living handbook of narratology. Disponível em: http://wikis.sub.uni-hamburg.de/ lhn/index.php/Focalization (Acessado em junho de 2015).

ANTUNES, António Lobo. Que cavalos são aqueles que fazem sombra no mar? Lisboa: Dom Quixote, 2009. 
ARNAUT, Ana Paula. A escrita insatisfeita e inquieta(nte) de António Lobo Antunes. In: CAMMAERT, Felipe (org.). António Lobo Antunes. A arte do romance. Lisboa: Texto, 2011.

BARTHES, Roland. O prazer do texto. 6. ed. Trad. J. Guinzburg. São Paulo: Perspectiva, 2013.

BECKETT, Samuel. O inominável. Trad. Ana Helena Souza. São Paulo: Globo, 2009.

CAMMAERT, Felipe (org.). António Lobo Antunes. A arte do romance. Lisboa: Texto, 2011.

CABRAL, Eunice et al. (org.). A escrita e o mundo em António Lobo Antunes. Actas do Colóquio Internacional da Universidade de Évora. Lisboa: Dom Quixote, 2003.

CAZALAS, Inès (2001). O romanesco na obra de António Lobo Antunes: herança, desconstrução, reinvenção. In: CAMMAERT, Felipe (org.). António Lobo Antunes. A arte do romance. Lisboa: Texto, 2011.

CORDEIRO, Cristina Robalo. Os limites do romanesco. Colóquio Letras. Fundação Calouste Gulbenkian, n.143/144. 1997, p. 111-133.

DELEUZE, Gilles; GUATTARI, Félix. Introdução: Rizoma. In: . Mil Platôs. 2a . ed. Trad. Ana Oliveira, Ana Guerra Neto e Célia Pinto Costa. São Paulo: 34, 2011. Vol. 1.

GIL, José. Fechamento e linhas de fuga em Lobo Antunes. In: CAMMAERT, Felipe (org.). António Lobo Antunes. A arte do romance. Lisboa: Texto, 2011.

ECO, Umberto. Obra aberta. Forma e indeterminação nas poéticas contemporâneas. 9a ed., $4^{\text {a }}$ reimp. Trad. Giovanni Cutolo. São Paulo: Perspectiva, 2013.

JAHN, Manfred. "More Aspects of Focalization: Refinements and Applications". In: Pier, John (ed.). GRAAT: Revue des Groupes de Recherches Anglo-Américaines de L'Université François Rabelais de Tours, Tours, 1999, n. 21, p. 85-110.

RICHARDSON, Brian. Narrative Poetics and Postmodern Transgression: Theorizing the Collapse of Time, Voice, and Frame. Narrative. Vol. 8, n. 1, 2000, p. 23-42.

SEIXO, Maria Alzira. Os romances de António Lobo Antunes: análise, interpretação, resumos e guiões de leitura. Lisboa: Dom Quixote, 2002. 


\section{NOTAS}

1 Professora do Departamento de Letras Vernáculas e do Programa de Pós-Graduação em Letras, da Universidade Federal de Santa Maria. Possui mestrado e doutorado dedicados à literatura portuguesa e, em 2014, cumpriu estágio pós-doutoral na Universidade de Coimbra.

2 Barthes utiliza a denominação "narrativa mais clássica", para designar romances como os de Zola, Balzac, Dickens, Tolstói, que atraem nossa leitura sobretudo pela anedota (2013, p. 18), e "narrativa moderna", "texto-limite", para designar o que atrai nosso interesse sobretudo pelo "volume da linguagem" (2013, p. 19). De qualquer forma, entre tais tendências que se sobressaem na heterogeneidade das formas do século XVIII, XIX e XX, entre o texto de prazer e o texto de fruição, "não há senão uma diferença de grau": "o texto da fruição é apenas o desenvolvimento lógico, orgânico, histórico, do texto de prazer [...] o hoje sai do ontem, Robbe-Grillet já está em Flaubert.... Mesmo implicando forças paralelas e intercomunicáveis, o texto de fruição (como o novo romance francês privilegiado por Barthes) surge sempre à maneira de um escândalo, ele é sempre o traço de um corte (2013, p. 28). Como narrativa contemporânea, entendemos sobretudo aquela produzida na segunda metade do século XX.

3 A prof. Inès Cazalas, no artigo "O romanesco na obra de António Lobo Antunes: herança, desconstrução, reinvenção", destaca essa apreciação do autor como "um dos escritores contemporâneos menos acessíveis" (2011).

4 Em O Inominável, tais tipos de questionamentos do narrador em relação a si e ao que narra são frequentes, por exemplo: "parece que falo, não sou eu, de mim, não é de mim" (2009, p. 29).

5 Aspectos que configuram a natureza da focalização do narrador/personagem:

(A) affect (fear, pity, joy, revulsion, etc.)

(B) perception:

(i) ordinary/primary/literal perception (vision, audition, touch, smell, taste, bodily sensation);

(ii) imaginary perception (recollection, imagination, dream, hallucination, etc.)

(C) conceptualization (thought, voice, ideation, style, deixis, etc.) (JAHN, 1999, p. 89-90).

6 “à medida que os romances vão ganhando vozes, ou melhor, à medida, que vão sendo concedidas vozes às personagens do mundo ficcional - cada uma delas recuperando parcelas de tempos e vivências próprios ou de outrem - a narrativa torna-se progressivamente mais fragmentária e, por consequência, mais desordenada, mais confusa" (ARNAUT, 2009, p.32). 